\title{
Do Monkeys Avoid Areas of Home Range Overlap Because They Are Dangerous? A Test of the Risk Hypothesis in White-Faced Capuchin Monkeys (Cebus capucinus)
}

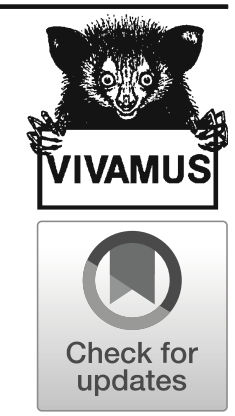

\author{
Lucía L. Tórrez-Herrera $^{1}$ • Grace H. Davis ${ }^{1,2}$ (D) Margaret C. Crofoot ${ }^{1,2,3,4,5}$
}

Received: 22 March 2019 / Accepted: 12 September 2019 / Published online: 1 February 2020

(C) The Author(s) 2020

\begin{abstract}
In social animals, areas where the home ranges of neighboring groups overlap are often underused. The Risk Hypothesis posits that the costs of intergroup conflict create a "landscape of fear," discouraging the use of such shared areas. To test this hypothesis, we observed the behavior of white-faced capuchins (Cebus capucinus) in central vs. peripheral areas of their home ranges. If capuchins perceive areas of home range overlap as "risky," we predicted they would change activity budgets, vocalization rates, and foraging behavior in these areas. A spatially explicit behavioral comparison based on nearly $100 \mathrm{~h}$ of focal follows revealed that capuchins socialize less in the periphery (vs. the center) of their home range. Time spent resting, foraging, and engaging in vigilance, as well as vocalization rates, varied in consistent ways across all four study groups, but these differences did not reach statistical significance. Fruit trees near range borders (vs. the center) contained more ripe fruit, and groups spent more time in these trees, with more individuals entering to feed and consuming more fruits. However, capuchins did not alter their foraging behavior in potentially risky peripheral areas in a manner consistent with predictions of optimal foraging theory: intake rates at patch departure were not significantly lower and groups depleted trees to a greater extent along the periphery vs. in the center of their range. These results suggest that while peripheral areas are perceived as risky and this "landscape of fear" contributes to behavioral changes, they also provide resources whose value may outweigh the cost of intergroup encounters.
\end{abstract}

Keywords Home range · Intergroup interactions · Intergroup competition · Landscape of fear - Optimal foraging theory $\cdot$ Risk-sensitive foraging

Handling Editor: Sarie van Belle

Grace H. Davis

ghdavis@ucdavis.edu

Margaret C. Crofoot

mcrofoot@ab.mpg.de

Extended author information available on the last page of the article 


\section{Introduction}

While many social animals actively defend part or all of their home range against intrusions by neighboring groups (Hensche and Skinner 1991; Hölldobler and Lumsden 1980; Kelly 2005; Lawes and Henzi 1995; Watts and Mitani 2001), it is rare for territorial encounters to be so violent that they result in serious injuries or death (Boesch et al. 2007; Mech 1994; Miller 1998; Palombit 1993; Wilson and Watts et al. 2006; Wilson and Wrangham 2003). In species that do engage in lethal territorial aggression, areas where the home ranges of neighboring groups overlap tend to be underused, e.g., ants (Oecophylla longinoda: Hölldobler and Lumsden 1980), wolves (Canis simensis: Sillero-Zubiri and Macdonald 1998; Canis lupus: Mech and Harper 2002), and chimpanzees (Pan troglodytes: Wilson et al. 2007). These "buffer zones" can have important organizational effects on community ecology, creating, for example, safe havens for prey species that may generate source-sink dynamics at the population level, e.g., wolf (Canis lupus) and white-tailed deer (Odocoileus virginianus) populations (Mech 1977; Mech et al. 1980) and chimpanzee (Pan troglodytes) and red colobus monkey (Colobus badius) (Stanford 1995).

To explain this phenomenon, Wrangham et al. (2007) proposed the "Risk Hypothesis," which suggests that in species where territorial confrontations can be lethal, the risk of fatal encounters leads individuals to avoid areas where they might meet neighboring groups. However, their comparison of the ranging patterns of three primate species that vary in the intensity of their intergroup conflict failed to find the predicted differences in space use (Wrangham et al. 2007). Species in which lethal territorial aggression is rare (white-faced capuchin monkeys, Cebus capucinus) or nonexistent (red-tailed monkeys, Cercopithecus ascanius) still underuse shared areas to a similar degree as chimpanzees (Pan troglodytes), whose intergroup conflicts are notoriously violent (Boesch et al. 2007; Watts et al. 2006; Wilson et al. 2004). Although these findings are not consistent with the idea that lethal intergroup aggression, per se, is responsible for the emergence of "buffer zones," they leave open the possibility that the core logic of the Risk Hypothesis is correct: primates perceive intergroup interactions to be costly, even if they are unlikely to be lethal. If this is the case, we predict that in a wide range of species with agonistic intergroup relationships, individuals will alter their behavior in the periphery of their range in ways that are consistent with theory about how animals respond to elevated risk.

Spatial variation in risk across an animal's home range generates a "landscape of fear," which has been shown to cause modifications in foraging behavior (Atkins et al. 2019; Emerson et al. 2011; Laundré et al. 2001). Specifically, foraging under risk requires animals to trade off their needs for food and safety (McNamara 1987; Sih 1980). Animals will often decrease their activity in risky areas or shift their ranging to use safer parts of the habitat (Sih 1980; Werner et al. 1983). While "landscapes of fear" have generally been studied in the context of predation risk, aggressive contact with neighbors can also generate spatial heterogeneity in risk landscapes (Willems and Hill 2009). Optimal foraging theory provides a useful framework for understanding how animals balance their energetic requirements while reducing their risk of injury or death (Charnov 1976; Stephens and Krebs 1986). In response to risk, models predict that foragers should abandon food patches sooner, leaving behind more food (Brown 1988; Gilliam and Fraser 1987). In addition, models derived from the marginal value theorem 
(Charnov 1976) predict that foragers should leave patches when the rate of energetic gain ("harvest rate") no longer exceeds metabolic, predation, and missed opportunity costs of foraging (Brown 1988). As such, variation in the instantaneous rate of gain when foragers leave food patches (hereafter the "quitting harvest rate") has been shown to reflect the level of risk in the environment (Berger-Tal et al. 2009; Brown 1999; Brown and Kotler 2004; Brown et al. 1992). Foragers should leave food patches at a higher quitting harvest rate in high-risk areas compared to safer zones. While risksensitive foraging strategies have been described in depth for prey species (Lima 1998; Lima and Dill 1990; Orrock et al. 2010; Preisser et al. 2005), foraging under perceived risk of intergroup aggression remains underexplored (Emerson et al. 2011).

To investigate the possibility that the risk of territorial conflicts along home range borders are sufficiently costly to induce behavioral changes, we test whether whitefaced capuchins (Cebus capucinus, hereafter, capuchins) change their behavior in ways predicted by the Risk Hypothesis when they are in the center vs. at the periphery of their home range. While the home ranges of neighboring capuchin groups in our study population overlap significantly (range of dyadic overlap: 3.0-52.2\%; Crofoot 2007), the shared areas near the periphery are used less intensely than the central (unshared) core of each group's range (Wrangham et al. 2007). While intergroup conflicts in capuchins are universally agonistic (Crofoot 2007, 2012; Crofoot et al. 2008; Perry 1996), and can involve serious injury or death (e.g., Gros-Louis et al. 2003), no such incidents have yet been observed in this study population (Crofoot, unpubl. data).

If capuchins avoid areas of home range overlap because of the risks associated with territorial aggression, we predict that they will modify their behavior in ways that reflect this increased risk when they are in the periphery of their range. In this study, we tested for differences in activity budgets, vocalization rates, and foraging behaviors at the center versus the periphery of capuchin group home range areas. Specifically, we predicted that if areas of home range overlap are perceived to be "risky," capuchins will spend more time being vigilant and less time resting and socializing at the edge of their range. We also predicted that they will vocalize less frequently in border areas, so as to avoid alerting other groups to their presence (Wilson et al. 2007). Further, risk-sensitive foraging theory predicts that if areas of home range overlap are risky, capuchins will deplete food sources in these areas less thoroughly than patches located in safer, core areas (Caraco 1980; McNamara and Houston 1992; Sih 1980). Thus, if the possibility of aggressive intergroup encounters increases the risk of foraging in shared areas, we predicted that capuchins will spend less time in fruit trees, consume fewer fruits, and that fewer group members will feed when foraging in the periphery vs. in the center of their range. We further predicted that groups will have higher quitting harvest rates at patch departure, i.e., when they choose to stop foraging in one food patch and move on to the next (Brown 1988; Charnov 1976).

\section{Methods}

\section{Study Site}

We conducted this study at the Smithsonian Tropical Research Institute's field site on Barro Colorado Island (BCI), a 1560-ha island of semideciduous tropical lowland 
forest located in the Panama Canal $\left(9^{\circ} 09^{\prime} \mathrm{N} / 79^{\circ} 51^{\prime} \mathrm{W}\right)$. The mean annual temperature is $27^{\circ} \mathrm{C}$, with a daily variation of $9^{\circ} \mathrm{C}$. Precipitation per year varies from 2400 to 2800 mm, with an 8-mo wet season (May-December) and 4-mo dry season (January-May). BCI lies approximately halfway along a strong gradient of precipitation that exists between Panama's Caribbean (wet) and Pacific (dry) coasts.

\section{Study Species}

White-faced capuchins (Cebus capucinus) are Neotropical primates that range from northern Honduras to Panama in Central America, and along the west of the Colombian Andes to the northwest of Ecuador in South America. They are the only species of the genus Cebus reported in Central America. They live in a range of habitats, including mature deciduous forests, secondary forests, marshes, mangroves, and gallery forests (Fragaszy et al. 2004; Freese and Oppenheimer 1981). Capuchin monkeys are omnivorous. Their diet consists of fruit, flowers, leaves, pith, seeds, nectar, pollen, bird eggs, arthropods, and small vertebrates. The composition of their diet varies substantially across the day and over the seasons of the year (Fragaszy et al. 2004). Capuchin home ranges on BCI are 80-150 ha in size and overlap extensively with those of neighboring capuchin groups (Crofoot 2007; Wrangham et al. 2007). Intergroup encounters occur frequently in the capuchin population on BCI ( $c a$. 1 intergroup encounter every other day, Crofoot 2007). The outcome of intergroup encounters is influenced by the relative size of the competing groups and the location of the interaction (Crofoot and Gilby 2012; Crofoot et al. 2008).

\section{Data Collection}

The capuchins on BCI have been studied nearly continuously since 2004, but sampling protocols and the study groups under observation have varied over the years. Data used in this article come from two main study periods.

Period 1: From February 2009 through January 2010, we collected behavioral data on four habituated groups of white-faced capuchin monkeys with overlapping home ranges (Table 1, Fig. 1). All adult and subadult members of our study groups were individually identifiable based on distinctive physical characteristics. We collected data

Table 1 Group sizes and 95\% and 50\% kernel density home range estimates for study groups of white-faced capuchins (Cebus capucinus) on Barro Colorado Island, Panama, February 2009-January 2010 and JuneAugust 2016

\begin{tabular}{|c|c|c|c|c|c|c|}
\hline \multicolumn{4}{|c|}{$2009-2010$} & \multicolumn{3}{|l|}{2016} \\
\hline Group & $\begin{array}{l}\text { No. of } \\
\text { individuals }\end{array}$ & $\begin{array}{l}\text { Home range } 95 \% \\
\text { kernel (ha) }\end{array}$ & $\begin{array}{l}\text { Core area } 50 \% \\
\text { kernel (ha) }\end{array}$ & $\begin{array}{l}\text { No. of } \\
\text { individuals }\end{array}$ & $\begin{array}{l}\text { Home range } 95 \% \\
\text { kernel (ha) }\end{array}$ & $\begin{array}{l}\text { Core area } 50 \% \\
\text { kernel (ha) }\end{array}$ \\
\hline $\mathrm{FC}$ & 14 & 91.1 & 23.5 & 12 & 131.9 & 36.9 \\
\hline BLT & 10 & 71.6 & 19.3 & - & - & - \\
\hline $\mathrm{TB}$ & 8 & 82.9 & 20.9 & - & - & - \\
\hline Top & 14 & 81.2 & 33.7 & - & - & - \\
\hline
\end{tabular}




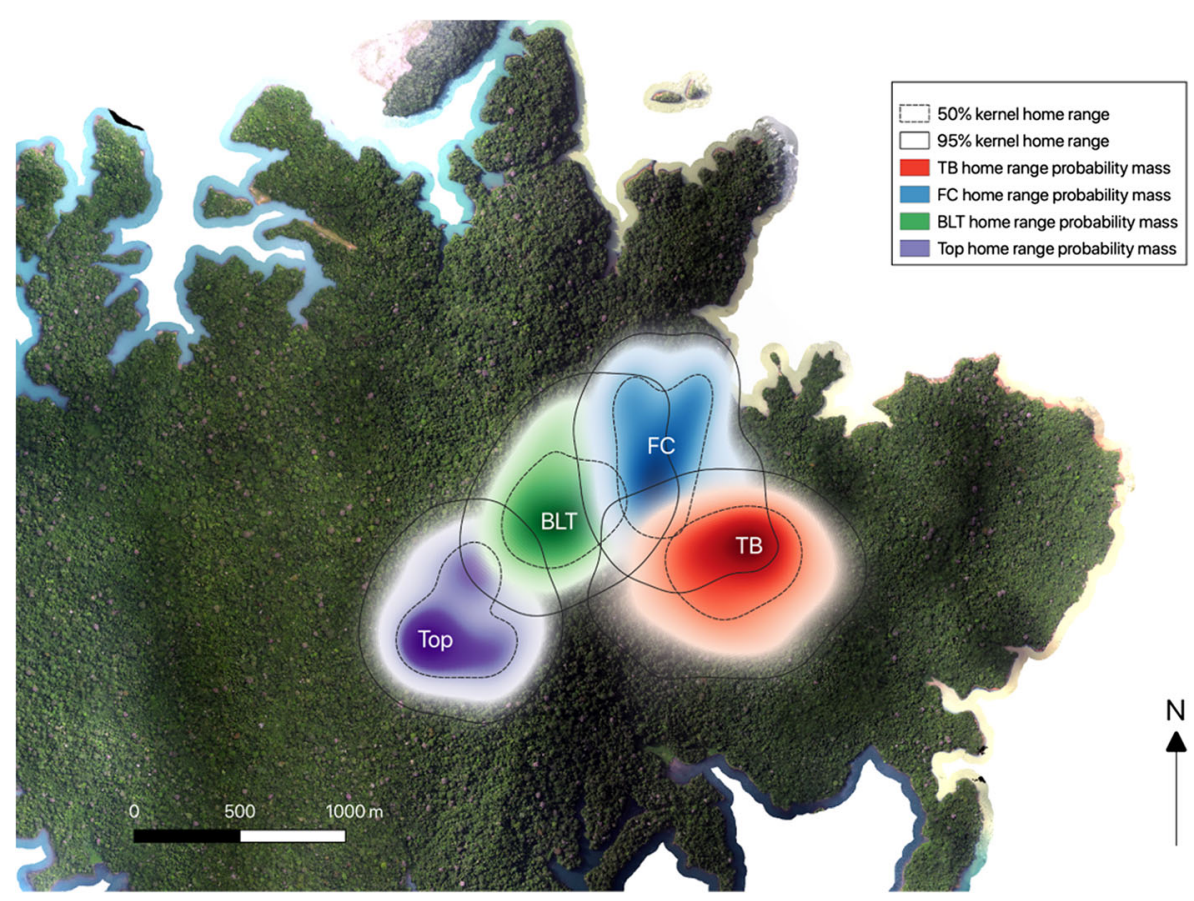

Fig. 1 Home ranges for white-faced capuchin (Cebus capucinus) study groups on Barro Colorado Island, Panama from February 2009 to January 2010. The probability mass for each group's home range is represented by color gradients (darker colors show higher probability mass). The $50 \%$ kernel home ranges are marked by dashed black lines, and $95 \%$ kernel home ranges are represented by solid black lines.

on individual behavior during randomized 10-min focal-individual follows (Altmann 1974). During these follows, we recorded the activity state of focal individuals every minute (rest, feed, forage, travel, vigilance/visual scanning, or social behavior) and tallied the number of vocalizations per minute on an all-events basis. We also took data on group-level movement; one observer would approximate the center of mass of the group and record a location coordinate every $10 \mathrm{~min}$ throughout observation time using a handheld GPS (Garmin GPS Map 60csx, Garmin Inc., Olathe, KS).

Period 2: From June to August 2016, we collected observational data on the foraging behavior of one habituated capuchin group (FC: one adult male, three adult females, seven juveniles, and one infant, Table 1, Fig. 2). Our data collection focused on Attalea butyracea palm trees (fruiting period: May-November; Adler and Lambert 2008), the primary food resource for capuchin monkeys in this population during this period (comprising $>80 \%$ of their total feeding time, G. H. Davis unpubl. data). A. butyracea fruits are highly clumped, growing on large infructescences (one to four per tree) that each suspend off a single stem of the palm. The size and shape of the fruit make it possible to observe and record every time any member of the group enters the food patch and removes fruit. We recorded data on FC's foraging behavior in each palm the group fed in during our observational follows $(N=95$; further detail provided in the text that follows). As in Period 1, we took data on group-level movement using a 


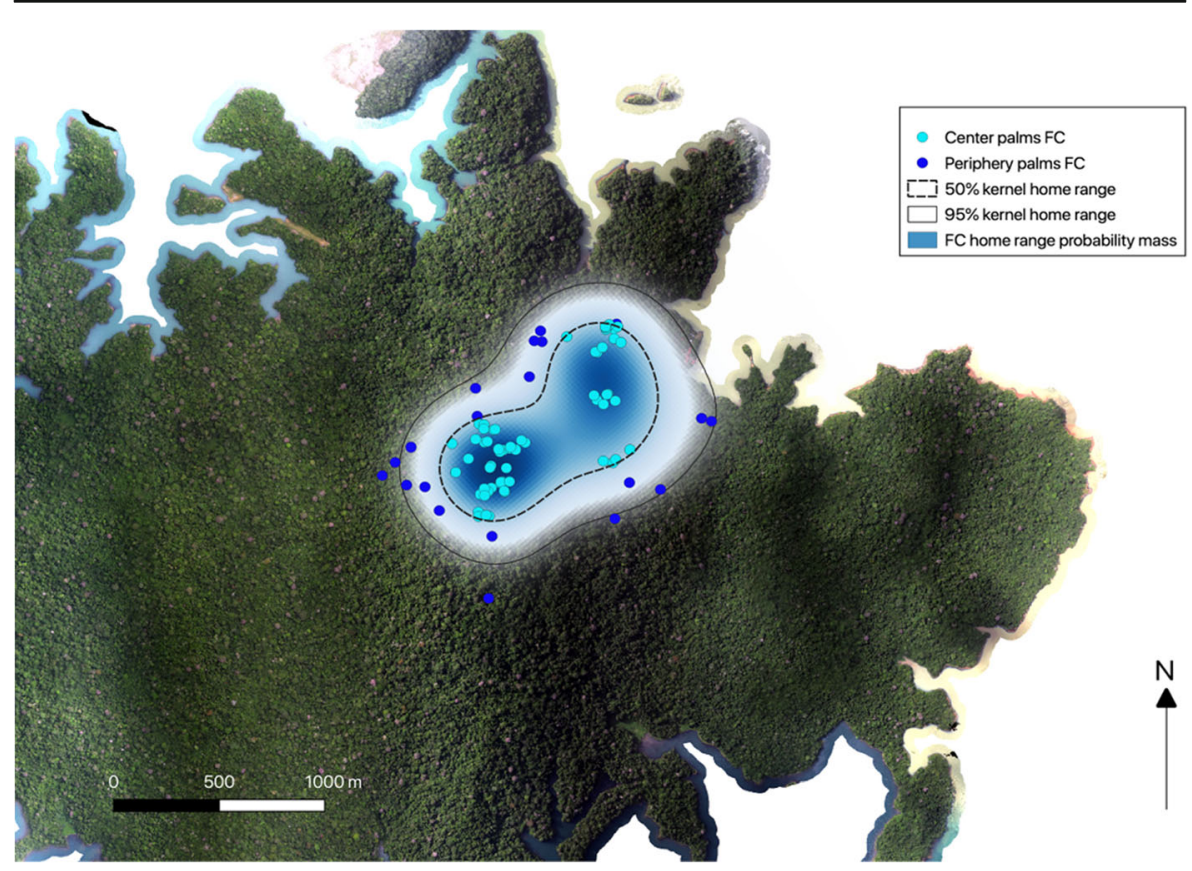

Fig. 2 Home range for white-faced capuchins (Cebus capucinus) belonging to FC group on Barro Colorado Island, Panama from June to August, 2016. The color gradient represents the probability mass for the home range (darker colors reflect higher intensity of use). The $50 \%$ kernel home range estimate is marked by a dashed black line, and the $95 \%$ kernel home range estimate is represented by a solid black line. Attalea butyracea palms where the group fed are marked by light blue circles (central trees within the 50\% kernel home range) and dark blue circles (peripheral trees outside the $50 \%$ kernel home range).

handheld GPS (Garmin GPS Map 60csx, Garmin Inc., Olathe, KS) to record a location every $10 \mathrm{~min}$ from the approximate center of mass of the group.

The white-faced capuchin population on BCI experienced a mass mortality event between November 2010 and January 2011, precipitated by an unexpected climatic event that brought unusually cold, wet weather to central Panama (annual mean precipitation $=2623 \mathrm{~mm}$, precipitation in $2010=4135 \mathrm{~mm}$; data provided by the Physical Monitoring Program of the Smithsonian Tropical Research Institute). During this cold front, which was accompanied by a delay in the ripening of the fruit of Dipteryx oleifera, a keystone species for frugivores, as much as $50 \%$ of the capuchin population died, leading to the dissolution of one of our study groups (BLT) and reduction in the size of the other three study groups (Crofoot unpubl. data). By 2016, FC had nearly regained its previous size, but differences in the strength of intergroup competition may exist between the two study periods.

\section{Space Use}

We used GPS data on the movement of each group's center of mass to calculate $50 \%$ and $95 \%$ kernel home range estimates using continuous time movement models implemented in the ctmm package in R (Alavi 2018; Calabrese et al. 2016). Conventional techniques for calculating home ranges, such as kernel density estimators 
(KDEs), assume independent and identically distributed data. However, tracking data on animal movement violate these assumptions, as they are inherently autocorrelated. Continuous time movement models (also known as continuous time stochastic processes) derive autocorrelated KDEs by approximating the underlying movement behavior of an animal using a model selection approach applied to the autocorrelation structure of an animal's movement (for more details on this method see Fleming et al. 2015, 2017, 2018). The bandwidth is optimized under the assumptions of the fitted movement model for autocorrelated kernel density estimation using the bandwidth function in the ctmm package.

Home range estimates are statistical descriptions of space use and do not necessarily reflect how animals perceive or respond to their environment. For this reason, we chose to test each of our predictions using two different definitions of central and peripheral areas. The first definition captures relative familiarity with the area, defining center and periphery as the areas falling inside and outside the $50 \%$ kernel home range, respectively. Capuchins use areas inside their 50\% kernel home range more intensely than areas outside this border (see probability mass distributions in Figs. 1 and 2), and thus may be more familiar with them. Our second definition captures the potential salience of home range boundaries as important landmarks, classifying all locations within $150 \mathrm{~m}$ of the $95 \%$ kernel contour as peripheral and all points within $150 \mathrm{~m}$ of the home range center (defined as the centroid of the $50 \%$ kernel) as central. The home range for one of our capuchin groups, FC, borders the lake edge where presumably risk of intergroup encounters is extremely low. We therefore classified all samples located on the side of FC's range bordering the lake as central.

\section{Activity Budgets}

To test if capuchins were more vigilant or spent more time searching for or eating food in the periphery vs. the center of their range, or if they rested or engaged in social behavior less often in the periphery, we fitted binomial generalized linear mixed models (GLMMs, Bolker et al. 2009) using the lme4 package in R 3.4.2 (R Development Core Team 2016). We used a zero-inflated binomial GLMM to test if capuchins vocalized more at the center than on the periphery of their range. We included individual identity as a random effect in all models to account for repeated sampling of the same individuals and included location (center vs. periphery) and group identity as fixed effects in all models. We applied a Bonferroni correction to our significance level to account for multiple testing $(\alpha=0.01)$.

\section{Foraging Behavior}

To investigate if capuchins alter their foraging behavior where the risk of intergroup encounters is high, we collected detailed data on FC's exploitation of fruit in Attalea butyracea palm trees, using the focal tree method (Vogel 2004). To obtain these data, four observers followed FC group. One observer moved to the front of the group during follows, attempting to anticipate which A. butyracea the group was likely to visit. When a group entered a palm, all four observers positioned themselves around the palm tree to get a complete view of the infructescence. For each foraging bout at an 
A. butyracea, we recorded the time the first group member arrived, each successive arrival, and the time of departure from the tree for all monkeys. We define the total "patch residency time" as the time between the entry of the first individual into the tree and the departure of the last individual out of the tree. Using the iOS application Animal Behaviour Pro (version 1.2, University of Kent 2012), we recorded the time (to the second) that each fruit was inspected (smelled, touched, or bitten), harvested, and consumed by a member of the group, as well as the identity of that individual. For each fruit harvested by a group member, we also recorded the percentage of pulp consumed (in categories: $25 \%, 50 \%, 75 \%$, and $100 \%$ ). With these data on intake rates, we calculated the total number of fruits consumed by each individual and by the group as a whole in each tree. We tested for differences in the mean number of fruits consumed by the group and the mean number of fruits eaten per capita in central vs. peripheral trees using Wilcoxon signed-rank tests (Wilcoxon 1945). We calculated the quitting harvest rate for the group as the instantaneous rate of gain measured when the group stopped feeding and left each palm tree-specifically, from the last fruit to the second to last fruit consumed by the group at the tree. We tested for differences in the quitting harvest rate at patch departure in trees located in the center vs. on the periphery of the group range using a Wilcoxon signed-rank test (Wilcoxon 1945). We compared the patch residency time and the number of individuals entering each tree in the center vs. on the periphery using Student's $t$-tests (we log transformed data to conform to assumptions of normality; Sokal and Rohlf 1987).

To quantify the patch size and quality of each palm where the group fed, we took photographs of the infructescences of a subset of Attalea butyracea trees immediately after group foraging events $(N=58)$. We took a total of two to five photographs per tree from multiple angles to ensure an accurate representation of the number and quality of available fruits. We used ImageJ software (ImageJ 1.52a, Wayne Rasband, National Institutes of Health, USA; http://imagej.nih.gov/ij; Schneider 2012) to standardize the color in each photograph and then counted the number of fruits of different stages of ripeness. As A. butyracea fruits change color as they ripen, fruits were separated into maturity categories based on color: ripe fruits (yellow/orange fruits with $<10 \%$ green), partially ripe fruits (fruits half yellow/orange and half green), and unripe fruits (green fruits with $<10 \%$ yellow/orange). As photos were taken immediately following group feedings and thus reflect the post-foraging patch size and quality, we obtained full pre-foraging counts of patch size and patch quality by summing the number of fruits counted in the photos and the number of fruits eaten by the group during the foraging event. We define patch size as the total number of fruits on the infructescence and patch quality as the total number of ripe fruits on the infructescence, as capuchins selectively eat ripe fruits. We compared patch size and patch quality for A. butyracea in the center vs. on the periphery of the group's home range using Wilcoxon signed-rank tests (Wilcoxon 1945). We also examined the extent to which the capuchins depleted trees (i.e., the number of ripe fruits remaining in the palm when the group departed) in central vs. peripheral areas using Wilcoxon signed-rank tests (Wilcoxon 1945). To look further at the extent of patch use and depletion, we calculated the proportion of available ripe fruits consumed by the group in trees at the center vs. the periphery of their range. We conducted all analyses in $\mathrm{R}$ version 3.4.2 (R Development Core Team 2018). 


\section{Ethical Note}

All research described in this article received clearance from the Smithsonian Tropical Research Institute Institutional Animal Care and Use Committee (assurance numbers 2008-03-12-08 and 2014-0717-2017) and the University of California, Davis Institutional Animal Care and Use Committee (A3433-01); complied with the laws of the Republic of Panama and the United States of America; and adhered to the American Society of Primatologists Principles for the Ethical Treatment of Nonhuman Primates and the International Primatological Society Code of Best Practices for Field Primatology. The authors declare that they have no conflict of interest.

\section{Data Availability}

The data sets generated and analyzed for this study, along with annotated $\mathrm{R}$ files, are available from the authors upon request.

\section{Results}

Patterns of Behavior in Central vs. Peripheral Areas

Consistent with the hypothesis that risk is increased along home range borders, capuchins in all four of our study groups spent less time engaged in social behavior when they were at the periphery of their range than when they were in the center (binomial GLMM: $z=3.15, P=0.0001$; Fig. 3a). Although all groups displayed
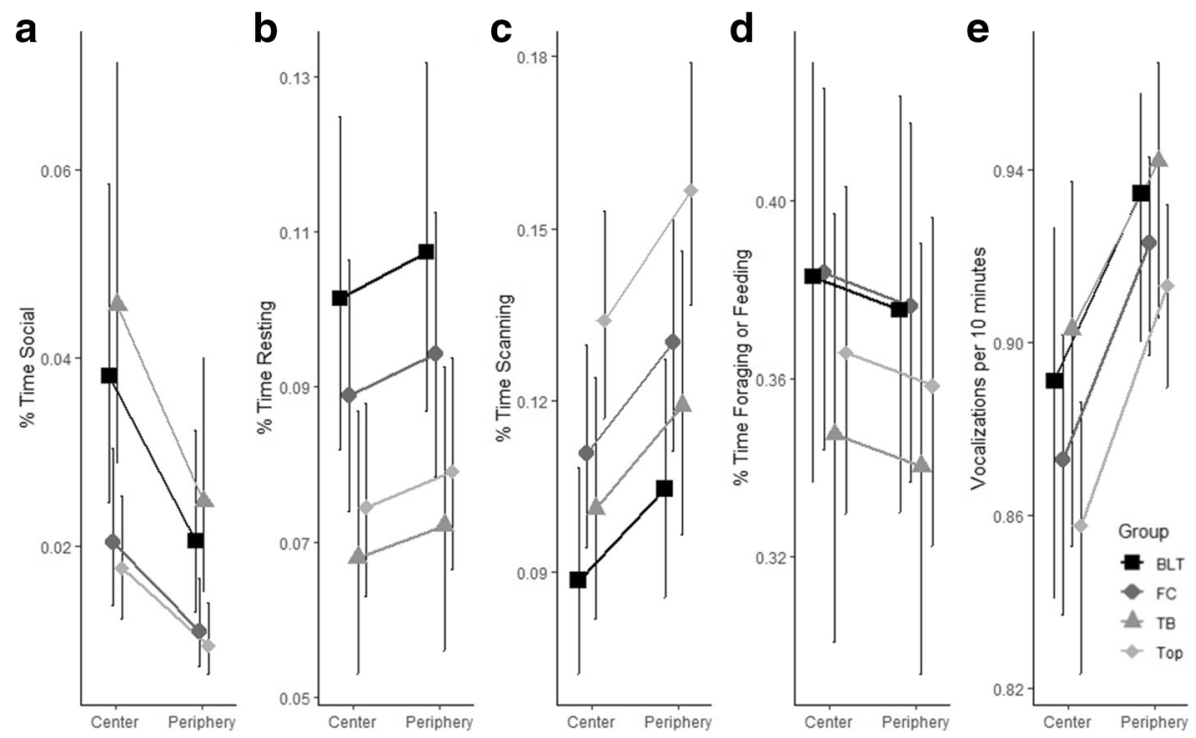

Fig. 3 Percent of time white-faced capuchins (Cebus capucinus) on Barro Colorado Island, Panama spent (A) engaging in social behavior, (B) resting, (C) scanning the canopy, and (D) foraging and feeding, as well as (E) the vocalization rate (number of calls per $10 \mathrm{~min}$ ) in the home range center vs. periphery for four capuchin groups (BLT, FC, TB, and Top), based on model predictions. Error bars represent the $95 \%$ confidence intervals around the mean. 
consistent differences in the spatial patterning of the other behaviors we investigated, after accounting for multiple testing (Bonferroni corrected $\alpha=0.01$ ), capuchins in our study groups did not show statistically significant differences in the amount of time they spent resting in central vs. peripheral areas (binomial GLMM: $z=-0.68, P=0.50$; Fig. 3b), were not significantly more vigilant (binomial GLMM: $z=-2.33, P=0.02$; Fig. 3c), and did not spend significantly more time feeding and foraging (binomial GLMM: $z=0.52, P=0.60$; Fig. $3 \mathrm{~d}$ ). They also did not vocalize more frequently in the center as compared to on the periphery of their home ranges (GLMM: $z=-1.91, P=$ 0.06; Fig. 3e). When we define group position based on the capuchins' distance from their home range center and home range boundary, the results of our statistical tests are broadly consistent. Capuchins spent less time engaged in social behavior when they were within $150 \mathrm{~m}$ of their home range border than when they were within $150 \mathrm{~m}$ of the geometric center of their range (binomial GLMM: $z=4.25, P=0.00002$ ) but did not differ in the amount of time they spent resting (binomial GLMM: $z=1.93, P=0.054$ ), scanning their surroundings (binomial GLMM: $z=-2.21, P=0.027$ ), feeding and foraging (binomial GLMM: $z=0.79, P=0.43$ ), or in their vocalization rate (GLMM: $z=-1.54, P=0.12)$ after applying a Bonferroni correction $(\alpha=0.01)$ to account for multiple statistical tests.

\section{Foraging Behavior in Central vs. Peripheral Areas}

We obtained data on the feeding behavior of capuchins in FC group in 95 Attalea butyracea trees (Fig. 2). Patch size (i.e., the total number of fruits in the palm prior to group feeding) did not differ significantly between trees located in the center vs. at the periphery of the group's home range (center: $\bar{x}=242.9 \pm$ SD 168.8 fruits, periphery: $\bar{x}=$ $321.5 \pm$ SD 165.7 fruits, Wilcoxon signed-rank test: $W=218, N_{\text {center }}=45, N_{\text {periphery }}=$ $13, P=0.168$ ). However, patch quality (i.e., the total number of ripe fruits available in palms prior to group feeding) was significantly higher at the periphery compared to in the center of the range (center: $\bar{x}=131.6 \pm 164.5$ ripe fruits, periphery: $\bar{x}=171.5 \pm 76.0$ ripe fruits, $W=153, N_{\text {center }}=45, N_{\text {periphery }}=13, P=0.012$, Fig. $4 \mathrm{a}$ ). Capuchins varied their foraging behavior depending on location. They spent significantly more time feeding in A. butyracea palms located at the periphery of their home range than in those located in the center (center: $\bar{x}=12.0 \pm 17.9$ min, periphery: $\bar{x}=24.5 \pm 29.2 \mathrm{~min}$, Student's $t$-test, two-tailed: $t=-2.24, \mathrm{df}=22.14, P=0.035)$, and more group members entered and fed in palms near the periphery of their range (center: $\bar{x}=4.3 \pm 2.9$ individuals, periphery: $\bar{x}=6.4 \pm 3.3$ individuals, $t=-2.56$, $\mathrm{df}=25.48, P=0.017$ ). Patches located at the periphery of FC's range provided a higher energetic payoff both at the group and individual levels. The total number of fruits consumed by the group (center: $\bar{x}=19.6 \pm 24.3$ fruits, periphery: $\bar{x}=50.4 \pm 58.5$ fruits, Wilcoxon signed-rank test: $W=405.5, N_{\text {center }}=78, N_{\text {periphery }}=17, P=0.013$ ), and the per capita consumption were significantly higher in peripheral vs. central trees (center: $\bar{x}=2.8 \pm 3.5$ fruits, periphery: $\bar{x}=7.2 \pm 8.4$ fruits, $W=474.5, N_{\text {center }}=78, N_{\text {periphery }}=17, P=0.047$, Fig. 4b). However, we did not find evidence that capuchins altered their foraging behaviors in potentially risky border areas in a manner consistent with the predictions of optimal foraging theory. The group's quitting harvest rate at the time of patch departure did not differ as a function of their location (center: $\bar{x}=2.1 \pm 4.4$ fruits/minute, periphery: $\bar{x}=$ $1.2 \pm 1$ fruits $/ \mathrm{min}$, Wilcoxon signed-rank test: $W=0.80, N_{\text {center }}=64, N_{\text {periphery }}=17, P=$ 

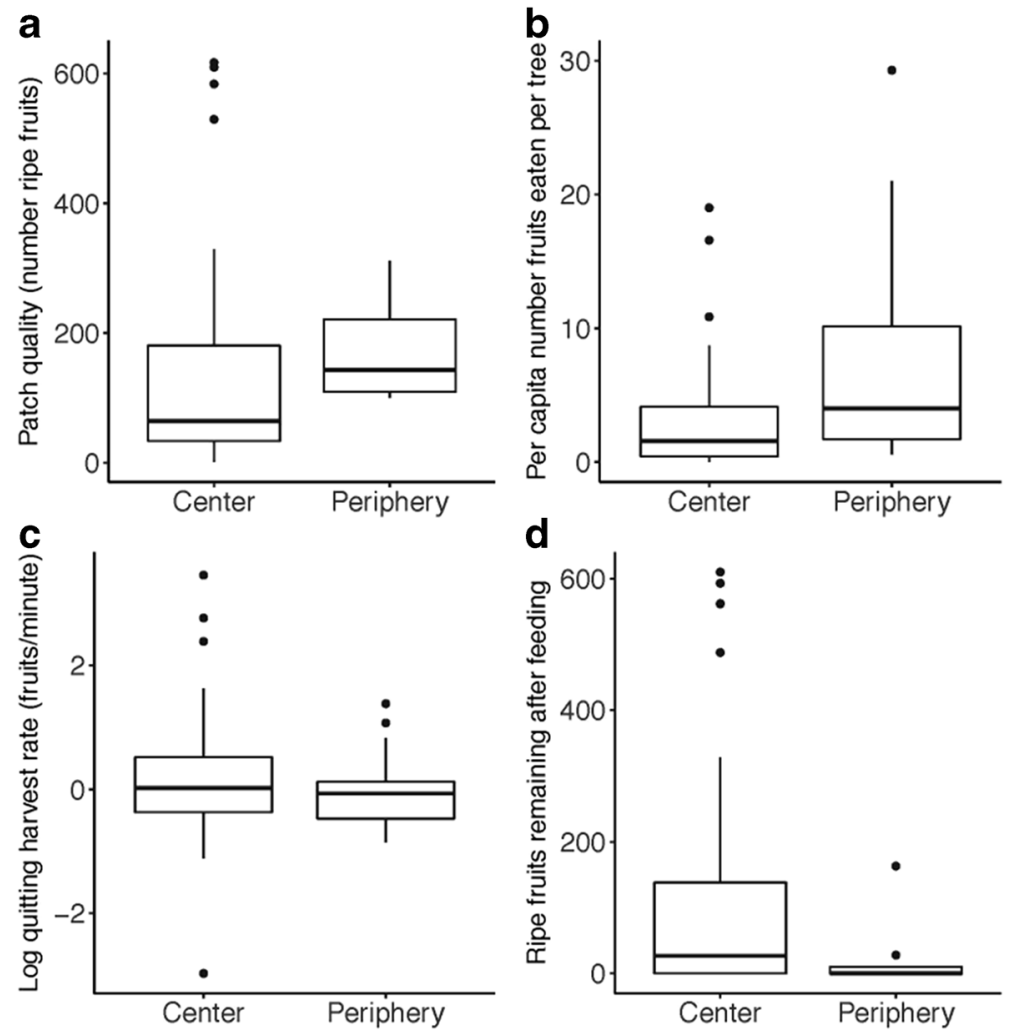

Fig. 4 Location-dependent foraging behavior of white-faced capuchins (Cebus capucinus) on Barro Colorado Island, Panama, June-August 2016. Comparison of Attalea butyracea palms in central vs. peripheral areas of FC group's home range: (a) patch quality (number of ripe fruits available in the palm prior to the start of the foraging bout), (b) mean per capita number of fruits consumed per palm, (c) log of the quitting harvest rate (in units of fruits harvested per minute) when groups departed palm trees, and (d) the number of ripe fruits remaining in the palm after feeding. In all boxplots, the bolded line represents the median and the box bounds the $50 \%$ interquartile range. Whiskers represent scores outside the $50 \%$ interquartile range. Outliers are marked by filled black circles.

0.429 , Fig. 4c). Further, capuchins depleted palms in peripheral areas to a greater extent than those in the center of their range, leaving fewer ripe fruits on the palms when they left the patch (center: $\bar{x}=105.8 \pm 166.3$ ripe fruits, periphery: $\bar{x}=16.3 \pm 44.8$ ripe fruits, $W=474.5, N_{\text {center }}=64, N_{\text {periphery }}=17, P=0.047$, Fig. $4 \mathrm{~d}$ ). They also consumed a greater proportion of the available ripe fruit in trees at the periphery of their range; the median proportion of ripe fruits consumed in periphery trees was $100 \%$ (i.e., the group consumed all available fruits in the palm), while for trees at the center, the median proportion of ripe fruits consumed was only $25 \%$.

We found similar results when we used our alternative definition of central and peripheral areas (i.e., within $150 \mathrm{~m}$ of the range centroid or range boundary). There was no difference in patch size (the total number of fruits available in the palm) for central versus peripheral trees (center: $\bar{x}=303.2 \pm 164.3$ fruits, periphery: $\bar{x}=321.5 \pm 165.7$ fruits, Wilcoxon signed-rank test: $W=57, N_{\text {center }}=20, N_{\text {periphery }}=12, P=0.303$ ) when we used this location-based classification. Palm trees within $150 \mathrm{~m}$ of the home range 
boundary did contain more ripe fruits than trees near the range center (center: $\bar{x}=25.7 \pm$ 22.5 ripe fruits, periphery: $\bar{x}=68.4 \pm 77.5$ ripe fruits, $W=286, N_{\text {center }}=20, N_{\text {periphery }}=$ $12, P=0.044)$. The group spent more time feeding (center: $\bar{x}=11.23 \pm 9.7 \mathrm{~min}$, periphery: $\bar{x}=25.5 \pm 29.8 \mathrm{~min}$, Student's $t$-test, two-tailed: $t=-1.70, \mathrm{df}=27.13, P=$ 0.050 ), and more individuals in the group fed (center: $\bar{x}=4.7 \pm 3.0$ individuals, periphery: $\bar{x}=6.4 \pm 3.4$ individuals, $t=-1.86$, $\mathrm{df}=31.07, P=0.035$ ) in palm trees along their home range boundary. The group as a whole consumed more fruits in trees near the boundary of their range compared to those in centrally located areas (center: $\bar{x}$ $=19.8 \pm 17.3$ fruits, periphery: $\bar{x}=58.5 \pm 63.1$ fruits, $W=428.5, N_{\text {center }}=39, N_{\text {periphery }}=$ $14, P=0.008)$. Individuals also obtained more fruits per capita in peripheral palms compared to palms within $150 \mathrm{~m}$ of the home range centroid (center: $\bar{x}=3.7 \pm 1.9$ fruits, periphery: $\bar{x}=6.9 \pm 5.2$ fruits, $W=414, N_{\text {center }}=39, N_{\text {periphery }}=14, P=0.019$ ), but there was no difference in the quitting harvest rate at the time of group departure (center: $\bar{x}=2.1 \pm 3.2$ fruits $/ \mathrm{min}$, periphery: $\bar{x}=1.2 \pm 1.0$ fruits $/ \mathrm{min}, W=296.5, N_{\text {center }}=$ $39, N_{\text {periphery }}=14, P=0.636$ ). Capuchins depleted trees located within $150 \mathrm{~m}$ of the home range boundary more thoroughly than those within $150 \mathrm{~m}$ of the range centroid (center: $\bar{x}=60.1 \pm 102.9$ fruits, periphery: $\bar{x}=16.3 \pm 44.8$ fruits, $W=140.5, N_{\text {center }}=20$, $N_{\text {periphery }}=12, P=0.036$ ). Finally, capuchins left fewer ripe fruits behind in palm trees along the home range boundary: the group consumed, on average, $100 \%$ of available ripe fruits in boundary trees, compared to only $58 \%$ for centroid trees (as reflected by the median proportion of ripe fruits consumed).

\section{Discussion}

Although white-faced capuchins underuse areas where their home ranges overlap with those of their neighbors, our comparisons of patterns of behavior in central vs. peripheral parts of their range only partially support the hypothesis that they consider these shared areas to be dangerous. If the Risk Hypothesis (as we have broadly interpreted it) explains capuchins' highly uneven patterns of space use, we predicted that their behavioral decisions in overlap zones would reflect elevated risk; they would engage in fewer discretionary activities (i.e., socializing and resting), invest less in foraging, show increased vigilance (i.e., scanning of their surroundings), and decrease the likelihood of being detected by neighbors by vocalizing less often. While capuchins in all four study groups spent less time engaged in social activities near the border of their home range, we did not find statistically significant differences in patterns of resting, foraging, and vigilance behavior and rates of vocalization. However, our study groups did vary their resting, foraging, and vigilance behavior in a consistent manner, depending on their location within their home ranges. All four groups spent more time resting and scanning their surroundings and less time engaged in feeding and foraging at the periphery of range as compared to in the center (Fig. 3b-d). The consistency of these patterns across groups is striking and suggests that although our study failed to detect a statistically significant difference in these behaviors, small, but potentially biologically relevant, effects may nonetheless exist. Although capuchins did not extensively change their behavior at the edge of their range where they may encounter neighbors, they socialized less in these peripheral areas. As social behaviors often occur in a relaxed context, this finding is consistent with the hypothesis that capuchins 
perceive these areas to be dangerous and may be fearful and/or highly alert. Consistent with this interpretation, individuals in all four of our study groups showed increased vigilance (in the form of visual scanning of the surroundings) at the edge of their home ranges, although this difference in behavior was not statistically significant. In addition, some demographic classes of individuals may experience greater risk in areas of home range overlap. For example, infanticide is known to occur in this species (Fedigan 2003; Manson et al. 2004), meaning that dependent young may be particularly vulnerable during aggressive intergroup encounters (Arseneau-Robar et al. 2017). The data used in this study, however, include focal follows only on adult and subadult group members. Additional research would thus be needed to determine if juveniles or infants alter their behavior near their home range borders and test the hypothesis that they experience greater risk than their mature group mates.

In contrast to what has been found in chimpanzees (Wilson et al. 2007), capuchins did not vocalize less frequently in areas of home range overlap. Individuals in all four of our study groups showed a (nonsignificant) tendency to vocalize at higher rates along the periphery of their home range compared to the center. One possibility is that capuchins vocalize more frequently in areas of home range overlap to alert other groups to their presence. This could be a form of territorial resource defense (Van Schaik et al. 1992) and/or function to reduce direct intergroup conflict (Waser 1975). However, it remains possible that capuchins modified their vocalizations to avoid detection, for example producing different types of calls, or decreasing the intensity of their vocalizations at the edge of their range. Further research specifically focused on vocal communication would be required to test these possibilities.

Our findings suggest that indirect feeding competition (i.e., scramble competition) between social groups creates significant heterogeneity in the spatial distribution of food resources within capuchin home ranges. Although Attalea butryacea palms did not differ in their fruit production as a function of their location within FC group's home range, trees on the periphery of the range contained significantly more ripe fruit. The higher patch quality at the periphery may be because groups tend to underuse the areas of their range that they share with neighbors (Wrangham et al. 2007). Consequently, peripheral fruit trees in these overlap zones appear to be exploited less frequently than trees in central areas and thus contain more ripe fruit. This difference in resource quality had measurable impacts on capuchin foraging behavior. Our study group spent more time feeding during visits to palm trees at the periphery of their range, consuming a greater number of fruits overall and a greater number of fruits per capita.

One of the most striking location-based differences in capuchin foraging behavior was the degree to which they depleted patches of palm fruit. Our study group depleted palm trees to a much greater extent near the borders of their range, often removing all ripe fruits (the median percent depletion for periphery trees was $100 \%$ vs. $25 \%$ depletion in central trees). This difference in depletion dynamics is consistent with our observation that capuchins spend more time in these trees and obtain more food from them (both for the group as a whole and per capita), but is puzzling in light of optimal foraging theory, which predicts that animals will leave food patches before all available food has been consumed (Charnov 1976; McNair 1982). Differences in the density of palms in central vs. peripheral areas could account for this pattern. The marginal value theorem predicts that foragers should exploit food patches more intensely when the density of patches is low (and thus the travel time between 
patches is high; Charnov 1976). The Attalea butyracea palms that capuchins exploited during our study were concentrated mainly in two areas of FC's home range, and the group's ranging was concentrated around these two focal areas (Fig. 2). As a result, their interpatch travel time between fruiting trees was higher on the periphery than in the center of their range. It is also possible that these differences in patch depletion are part of a strategy capuchins use to get the most out of their visits to risky areas where they may encounter neighbors. By visiting only the highest quality trees near their range boundary and fully harvesting the fruit crops, capuchins may be targeting resources that provided enough energetic payoff to outweigh the risk. Lastly, capuchins may be engaging in an interesting competitive tactic. By overexploiting resources in contested areas, capuchins lower the value of these shared areas and may be engaging in a form of indirect home range defense.

The benefits of foraging on high-quality food patches near the home range border appear to be shared widely among the members of our study group. More individual capuchins entered and fed in peripherally located palms compared to centrally located trees. This is likely due to the larger quantity of ripe fruit available in trees at the periphery of the range, which allows more members of the group to feed before the patch becomes depleted. However, it is also possible that capuchin groups are more cohesive in risky areas, resulting in more group members feeding together. While increasing the number of cofeeders in a palm results in increased within-group competition over resources, it may also provide protection by potentiating joint defense during aggressive encounters with neighbors. Numeric superiority has been shown to have an important impact on the outcome of competitive intergroup encounters in this population (Crofoot et al. 2008), and recruiting a large number of group members to participate in intergroup interactions is likely key to maintaining access to areas of home range overlap. Further, increased cohesion may improve the chances of detecting neighboring groups, or dilute the per capita risk of injury if an aggressive encounter does occur. Increased group cohesion could thus be a strategy to minimize risk in areas where encounters with neighbors can occur and may be potentiated by changes in the behavior of socially dominant individuals. Socioecological theory predicts that contest competition between groups should promote more tolerant and egalitarian relationships within groups, as high-ranking individuals need the support of low-ranking group members during conflicts with neighbors (Sterck et al. 1997). While this idea has generally been explored in comparisons between primate species (Isbell 1991; Matsumura 1999; Sterck and Steenbeek 1997; Willems and van Schaik 2015), the same processes could, in theory, drive spatiotemporal variation in a group's social dynamics. In capuchins, high rank confers priority access to food and the ability to displace others and monopolize important resources (Di Bitetti and Janson 2001; Janson 1990). However, in peripheral areas that overlap with neighboring groups, the need for greater cooperation during intergroup encounters may lead to decreased despotic behaviors during foraging, resulting in higher numbers of cofeeders. Future studies on group cohesion and cofeeding tolerance in risk-prone areas will elucidate these explanations.

Studies of numerous species have demonstrated that animal foraging behavior varies as a function of predation risk in a manner consistent with the predictions of optimal foraging theory (Altendorf et al. 2001; Brown 1988, 1999; Lima and Bednekoff 1999; Olsson et al. 2002). Specifically, theory predicts that animals should leave food patches at higher quitting harvest rates when risk is high. Risk has generally been thought of in 
terms of predation in most empirical studies, but some evidence suggests that risks of intergroup encounters may prompt similar changes in primate foraging behavior (Emerson et al. 2011). In contrast, in our study, the quitting harvest rate was not significantly different at the periphery vs. in the center of our capuchin study group's home range. One possible explanation is that the capuchins are trading off foraging rate with vigilance near their home range borders. In other words, groups may be "wasting" time looking out for their neighbors (see Brown 1999 for model predictions of vigilance-foraging trade-offs). Although we didn't find a statistically significant difference in rates of vigilance in these two areas, all four groups engaged in more vigilance at the edge of their range (Fig. 3C). Our activity budget data was based on a focal-individual scan sampling methodology, which may simply have provided too coarse a measure of behavior to detect such potentially subtle differences. Further data collection focused on fine-scale vigilance behavior in foraging patches is needed to properly test this hypothesis.

Capuchin groups consistently underuse areas of their home range where their territories overlap with neighboring groups (probability mass distributions, Fig. 1). Our behavioral data suggest that capuchins perceive these peripheral areas to be risky, supporting the hypothesis that areas of home range overlap are underused because they are actively avoided. However, there are several alternate (but not mutually exclusive) hypotheses that may explain this pattern of space use. Simple null models of animal movement often yield home ranges where peripheral areas are used less intensely than central areas (e.g., van Moorter et al. 2009). Further, if animals focus their ranging where resources are abundant, by definition, the interstices between ranges will be comparatively resource poor. Animals may then be selecting their home ranges simply based on where resources are found in the habitat, with core areas containing more resources than peripheral zones. The dynamics of intergroup scramble competition may also contribute to uneven patterns of space use by devaluing resources in shared areas by making them unpredictable (Caillaud et al. 2012; Crofoot et al. 2010).

The Risk Hypothesis proposes that the costs associated with aggressive intergroup encounters can explain why many animal species avoid areas of home range overlap where they may encounter their neighbors. In this study, we tested a wide range of predictions stemming from this hypothesis about how animals might alter their patterns of behavior in "risky" overlap zones. While our results did not support all of these predictions, we found significant evidence that capuchins adjust their behavior depending on where they are within their home range, and that some of these differences are consistent with the hypothesis that they perceive the borders of their range to be dangerous. Thus, the Risk Hypothesis may be a useful framework for investigating spatial variation in behavior in a wide range of animals, not only in species that engage in lethal territorial aggression. Further, our results suggest that the dynamics of intergroup relationships may generate significant heterogeneity in the distribution of food resources across the landscape. We found that fruit trees near range borders contain more ripe fruit, perhaps due to avoidance of these areas. The high energetic benefits that can be gained by foraging in these larger patches may explain why individuals continue to visit shared areas; ultimately, these resources appear to be "worth the risk." While some of our results are not consistent with theoretical predictions for risk-sensitive foraging, our data clearly demonstrate that capuchins exploit resources near the periphery of their range differently than those in the center. Whether 
these behavioral differences we observed reflect a trade-off between vigilance and foraging efficiency, or if the near total depletion of food patches in shared areas reflects a strategy of indirect range defense as we have suggested are promising directions for future research.

Acknowledgments We thank the Smithsonian Tropical Research Institute for permission to conduct this research, and for the important logistical support provided by members of the staff on Barro Colorado Island, particularly Melissa Cano, Oris Acevedo, and Adriana Bilgray. We thank Nena Robles, Anyuri González, Nohely Fossatti, Lynn Lewis-Bevan, and Daniel Herrera for their assistance in collecting field data; Robert Lessnau, Suzanne Murray, Diorine Smith, and Damien Caillaud for assistance with animal capture and veterinary support; and Shauhin Alavi, Damien Caillaud, and Mark Grote for their assistance with data analysis. Funding for this research was provided by grants to MCC from the Wenner-Gren Foundation, the Leakey Foundation, the National Science Foundation (BCS-1440755), and a Packard Foundation Fellowship. GHD received financial support for this research from a UC Davis Evolutionary Anthropology Summer Fellowship, the Hemispheric Institute of the Americas and the Tinker Foundation, the Explorer's Club, a Smithsonian Tropical Research Institute short-term fellowship, a UC Davis Provost's Fellowship, and an NSF Graduate Research Fellowship, as well as funding from the Leakey Foundation, National Geographic, and an NSF Doctoral Dissertation Research Improvement Grant.

Author Contributions MCC originally formulated the idea; MCC, LTH, and GHD developed the methodology, conducted fieldwork, performed statistical analyses, and wrote the manuscript.

Funding Information Open access funding provided by Max Planck Society.

Open Access This article is licensed under a Creative Commons Attribution 4.0 International License, which permits use, sharing, adaptation, distribution and reproduction in any medium or format, as long as you give appropriate credit to the original author(s) and the source, provide a link to the Creative Commons licence, and indicate if changes were made. The images or other third party material in this article are included in the article's Creative Commons licence, unless indicated otherwise in a credit line to the material. If material is not included in the article's Creative Commons licence and your intended use is not permitted by statutory regulation or exceeds the permitted use, you will need to obtain permission directly from the copyright holder. To view a copy of this licence, visit http://creativecommons.org/licenses/by/4.0/.

\section{References}

Adler, G. H., \& Lamber, T. D. (2008). Spatial and temporal variation in the fruiting phenology of palms in isolated stands. Plant Species Biology, 23, 9-17.

Alavi, S. E. (2018). Diet, cognition, and nutrient balancing in an orangutan habitat. PhD dissertation, Rutgers University School of Graduate Studies.

Altmann, J. (1974). Observational study of behavior: Sampling methods. Behaviour, 49(3), 227-267.

Atkins, J. L., Long, R. A., Pansu, J., Daskin, J. H., Potter, A. B., et al (2019). Cascading impacts of largecarnivore extirpation in an African ecosystem. Science, 346(6436), 173-177.

Altendorf, K. B., Laundré, J. W., López González, C. A., \& Brown, J. S. (2001). Assessing effects of predation risk on foraging behavior of mule deer. Journal of Mammalogy, 82(2), 430-439.

Arseneau-Robar, T. J. M., Taucher, A. L., Schnider, A. B., van Schaik, C. P., \& Willems, E. P. (2017). Intraand inter-individual differences in the costs and benefits of intergroup aggression in female vervet monkeys. Animal Behaviour, 123, 129-137.

Berger-Tal, O., Mukherjee, S., Kotler, B. P., \& Brown, J. S. (2009). Look before you leap: Is risk of injury a foraging cost? Behavioral Ecology and Sociobiology, 63(12), 1821-1827.

Boesch, C., Head, J., Tagg, N., Arandjelovic, M., Vigilant, L., \& Robbins, M. M. (2007). Fatal chimpanzee attack in Loango National Park, Gabon. International Journal of Primatology, 28(5), 1025-1034. 
Bolker, B. M., Brooks, M. E., Clark, C. J., Geange, S. W., Poulsen, J. R., et al (2009). Generalized linear mixed models: A practical guide for ecology and evolution. Trends in Ecology and Evolution, 24(3), 127135.

Brown, J. S. (1988). Patch use as an indicator of habitat preference, predation risk, and competition. Behavioral Ecology and Sociobiology, 22, 37-47.

Brown, J. S. (1999). Vigilance, patch use and habitat selection: Foraging under predation risk. Evolutionary Ecology Research, 1, 49-71.

Brown, J. S., \& Kotler, B. P. (2004). Hazardous duty pay and the foraging cost of predation. Ecology Letters, 7(10), 999-1014.

Brown, J. S., Morgan, R. A., \& Dow, B. D. (1992). Patch use under predation risk a test with fox squirrels, Sciurus niger. Annales Zoologici Fennici, 29(4), 311-318. Caillaud, D., Crofoot, M. C., Lewis, R. J., Scarpino, S. V., \& Meyers, L. A. (2012). Spatio-temporal distribution of food resources and group-level memory shape inter-group contact patterns in white-faced capuchins (Cebus capucinus) and Verreaux's sifaka (Propithecus v. verreauxi). American Journal of Physical Anthropology, 147, 110-110.

Calabrese, J. M., Fleming, C. H., \& Gurarie, E. (2016). Ctmm: An r package for analyzing animal relocation data as a continuous-time stochastic process. Methods in Ecology and Evolution, 7(9), 1124-1132.

Caraco, T., Martindale, S., \& Whittam, T. S. (1980). An empirical demonstration of risk-sensitive foraging preferences. Animal Behaviour, 28(3), 820-830.

Charnov, E. L. (1976). Optimal foraging, the marginal value theorem. Theoretical Population Biology, 9(2), 129-136.

Crofoot, M. C. (2007). Mating and feeding competition in white-faced capuchins (Cebus capucinus): the importance of short-and long-term strategies. Behaviour, 144, 1473-1495.

Crofoot, M., Caillaud, D., Salvador, L., Scarpino, S., Boyer, D., Ryan, S., \& Walsh, P. (2010). No need for violence: Episodic memory and scramble competition can explain primate "war zones." American Journal of Physical Anthropology, 141, 86-88.

Crofoot, M. C., \& Gilby, I. C. (2012). Cheating monkeys undermine group strength in enemy territory. Proceedings of the National Academy of Sciences of the USA, 109(2), 501-505.

Crofoot, M. C., Gilby, I. C., Wikelski, M., \& C., \& Kays, R. W. (2008). Interaction location outweighs the competitive advantage of numerical superiority in Cebu scapucinus intergroup contests. Proceedings of the National Academy of Sciences of the USA, 105(2), 577-581.

Di Bitetti, M. S., \& Janson, C. H. (2001). Social foraging and the finder's share in capuchin monkeys, Cebus paella. Animal Behaviour, 62(1), 47-56.

Emerson, S. E., Brown, J. S., \& Linden, J. D. (2011). Identifying Sykes' monkeys', Cercopithecus albogularis erythrarchus, axes of fear through patch use. Animal Behaviour, 81, 455-462.

Fedigan, L. M. (2003). Impact of male takeovers on infant deaths, births and conceptions in Cebus capucinus at Santa Rosa, Costa Rica. International Journal of Primatology, 24(4), 23-741.

Fleming, C. H., \& Calabrese, J. M. (2017). A new kernel density estimator for accurate home-range and species-range area estimation. Methods in Ecology and Evolution, 8(5), 571-579.

Fleming, C. H., Fagan, W. F., Mueller, T., Olson, K. A., Leimgruber, P., \& Calabrese, J. M. (2015). Rigorous home range estimation with movement data: A new autocorrelated kernel density estimator. Ecology, 96(5), 1182-1188.

Fleming, C. H., Sheldon, D., Fagan, W. F., Leimgruber, P., Mueller, T., et al (2018). Correcting for missing and irregular data in home-range estimation. Ecological Applications, 28(4), 1003-1010.

Fragaszy, D. M., Visalbergh, E., \& Fedigan, L. M. (2004). The complete capuchin: The biology of the genus Cebus. New York: Cambridge University Press.

Freese, C. H., \& Oppenheimer, J. R. (1981). The capuchin monkeys, genus Cebus. Ecology and Behavior of Neotropical Primates, 1, 331-390.

Gilliam, J. F., \& Fraser, D. F. (1987). Habitat selection under predation hazard: Test of a model with foraging minnows. Ecology, 68(6), 1856-1862.

Gros-Louis, J., Perry, S., \& Manson, J. H. (2003). Violent coalitionary attacks and intraspecific killing in wild white-faced capuchin monkeys (Cebus capucinus). Primates, 44, 341-346.

Henschel, J. R., \& Skinner, J. D. (1991). Territorial behaviour by a clan of spotted hyaenas Crocuta crocuta. Ethology, 88(3), 223-235.

Hölldobler, B., \& Lumsden, C. J. (1980). Territorial strategies in ants. Science, 210(4471), 732-739.

Isbell, L. A. (1991). Contest and scramble competition: Patterns of female aggression and ranging behavior among primates. Behavioral Ecology, 2(2), 143-155.

Janson, C. H. (1990). Ecological consequences of individual spatial choice in foraging groups of brown capuchin monkeys, Cebus paella. Animal Behaviour, 40, 922-934. 
Kelly, R. C. (2005). The evolution of lethal intergroup violence. Proceedings of the National Academy of Sciences of the USA, 102(3), 15294-15298.

Laundré, J. W., Hernández, L., \& Altendorf, K. B. (2001). Wolves, elk, and bison: Reestablishing the "landscape of fear" in Yellowstone National Park, U.S.A. Canadian Journal of Zoology, 79, 1401-1409.

Lawes, M. J., \& Henzi, S. P. (1995). Inter-group encounters in blue monkeys: How territorial must a territorial species be? Animal Behaviour., 49(1), 240-243.

Lima, S. L. (1998). Nonlethal effects in the ecology of predator-prey interactions. Bioscience, 48(1), $25-34$.

Lima, S. L., \& Bednekoff, P. A. (1999). Temporal variation in danger drives antipredator behavior: The predation risk allocation hypothesis. The American Naturalist, 153(6), 649-659.

Lima, S. L., \& Dill, L. M. (1990). Behavioral decisions made under the risk of predation: A review and prospectus. Canadian Journal of Zoology, 68(4), 619-640.

Manson, J. H., Gros-Louis, J., \& Perry, S. (2004). Three apparent cases of infanticide by males in wild whitefaced capuchins (Cebus capucinus). Folia Primatologica, 75(2), 104-106.

Matsumura, S. (1999). The evolution of "egalitarian" and "despotic" social systems among macaques. Primates, 40(1), 23-31.

McNair, J. N. (1982). Optimal giving-up times and the marginal value theorem. The American Naturalist, $119(4), 511-529$.

McNamara, J. M. (1987). Starvation and predation as factors limiting population size. Ecology, 68(5), 15151519.

McNamara, J. M., \& Houston, A. I. (1992). Risk-sensitive foraging: A review of the theory. Bulletin of Mathematical Biology, 54(2-3), 355-378.

Mech, L. D. (1977). Wolf-pack buffer zones as prey reservoirs. American Association for the Advancement of Science, 198(4314), 320-321.

Mech, L. D. (1994). Buffer zones of territories of gray wolves as regions of intraspecific strife. Journal of Mammalogy, 75(1), 199-202.

Mech, L. D., \& Harper, E. K. (2002). Differential use of a wolf, Canis lupus, pack territory edge and core. Canadian Field-Naturalist, 116, 315-316.

Mech, L. D., Peek, J., Korb, M., \& Rogers, L. (1980). Deer distribution in relation to wolf pack territory edges. The Journal of Wildlife Management, 44(1), 253-258.

Miller, L. E. (1998). Fatal attack among wedge-capped capuchins. Folia Primatologica, 69(2), 89-92.

Olsson, O., Brown, J. S., \& Smith, H. G. (2002). Long- and short-term state-dependent foraging under predation risk: An indication of habitat quality. Animal Behaviour, 63(5), 981-989.

Orrock, J. L., Dill, L. M., Sih, A., Grabowski, J. H., Peacor, S. D., et al (2010). Predator effects in predator-free space: the remote effects of predators on prey. The Open Ecology Journal, 3(10), 22-30.

Palombit, R. A. (1993). Lethal territorial aggression in a white-handed gibbon. American Journal of Primatology, 31(4), 311-318.

Perry, S. (1996). Female-female social relationships in wild white-faced capuchin monkeys, Cebus capucinus. American Journal of Primatology, 40(2), 167-182.

Preisser, E. L., Bolnick, D. I., \& Benard, M. F. (2005). Scared to death? The effects of intimidation and consumption in predator-prey interactions. Ecology, 86(2), 501-509.

Development Core Team, R. (2018). R: A language and environment for statistical computing. Vienna, Austria: R Foundation for Statistical Computing.

Schneider, C. A., Rasband, W. S., \& Eliceiri, K. W. (2012). NIH image to Image J: 25 years of image analysis HHS public access. Nature Methods, 9(7), 671-675.

Sih, A. (1980). Optimal behavior: Can foragers balance two conflicting demands? Science, 210(4473), 10411043.

Sillero-Zubiri, C., \& Macdonald, D. W. (1998). Scent-marking and territorial behaviour of Ethiopian wolves Canis simensis. Journal of Zoology, 245(3), 351-361.

Sokal, R. R., \& Rohlf, F. J. (1987). Introduction to biostatistics. New York: W. H. Freeman.

Stanford, C. B. (1995). The influence of chimpanzee predation on group size and anti-predator behaviour in red colobus monkeys. Animal Behaviour, 49(3), 577-587.

Steenbeek, R., \& Sterck, E. H. M. (1997). Female dominance relationships and food competition in the sympatric Thomas langur and long-tailed macaque. Behaviour, 134(9-10), 749-774.

Stephens, D. W., \& Krebs, J. R. (1986). Foraging theory. Princeton, NJ: Princeton University Press.

Sterck, E., Watts, D., \& van Schaik, C. (1997). The evolution of female social relationships in nonhuman primates. Behavioral Ecology and Sociobiology, 41, 291-309.

Van Moorter, B., Visscher, D., Benhamou, S., Börger, L., Boyce, M. S., \& Gaillard, J. M. (2009). Memory keeps you at home: A mechanistic model for home range emergence. Oikos, 118(5), 641-652. 
Van Schaik, C. P., Assink, P. R., \& Salafsky, N. (1992). Territorial behavior in Southeast Asian langurs: Resource defense or mate defense? American Journal of Primatology, 26(4), 233-242.

Vogel, E. R. (2004). The ecological basis of aggression in white-faced capuchins, Cebus capucinus, in a Costa Rican dry forest. $\mathrm{PhD}$ dissertation: Ecology and Evolution, Stony Brook University.

Waser, P. M. (1975). Experimental playbacks show vocal mediation of intergroup avoidance in a forest monkey. Nature, 255(5503), 56.

Watts, D. P., \& Mitani, J. C. (2001). Boundary patrols and intergroup encounters in wild chimpanzees. Behaviour, 138(3), 299-327.

Watts, D. P., Muller, M., Amsler, S. J., Mbabazi, G., \& Mitani, J. C. (2006). Lethal intergroup aggression by chimpanzees in Kibale National Park, Uganda. American Journal of Primatology, 68(2), 161-180.

Werner, E. E., Gilliam, J. F., Hall, D. J., \& Mittelbach, G. G. (1983). An experimental test of the effects of predation risk on habitat use in fish. Ecological Society of America, 64(6), 1540-1548.

Wilcoxon, F. (1945). Individual comparisons by ranking methods. Biometrics Bulletin, 1(6), 80-83.

Willems, E. P., \& Hill, R. (2009). Predator-specific landscape of fear and resource distribution on spatial range use. Ecology, 90(2), 546-555.

Willems, E. P., \& van Schaik, C. P. (2015). Collective action and the intensity of between-group competition in nonhuman primates. Behavioral Ecology, 26(2), 625-631.

Wilson, M. L., Hauser, M. D., \& Wrangham, R. (2007). Chimpanzees (Pan troglodytes) modify grouping and vocal behaviour in response to location-specific risk. Behaviour, 144(12), 1621-1653.

Wilson, M. L., Wallauer, W. R., \& Pusey, A. E. (2004). New cases of intergroup violence among chimpanzees in Gombe National Park, Tanzania. International Journal of Primatology, 25(3), 523-549.

Wilson, M. L., \& Wrangham, R. W. (2003). Intergroup relation in chimpanzees. Annual Review of Anthropology, 32, 363-392.

Wrangham, R., Crofoot, M., Lundy, R., \& Gilby, I. (2007). Use of overlap zones among group-living primates: A test of the 'risk hypothesis. Behaviour, 144(12), 1599-1619.

\section{Affiliations}

\section{Lucía L. Tórrez-Herrera $^{1} \cdot$ Grace H. Davis $^{1,2} \cdot$ Margaret C. Crofoot $^{1,2,3,4,5}$}

1 Smithsonian Tropical Research Institute, Panama City, Panama

2 Department of Anthropology, University of California, Davis, CA, USA

3 Animal Behavior Graduate Group, University of California, Davis, CA, USA

4 Department of Biology, University of Konstanz, Konstanz, Germany

5 Department for the Ecology of Animal Societies, Max Planck Institute for Animal Behavior, Konstanz, Germany 